\title{
Nonadhesive massive coiling endoscopic ultrasound-guided embolization in a single session for treatment of gastric varices: learning points of a technical variant
}
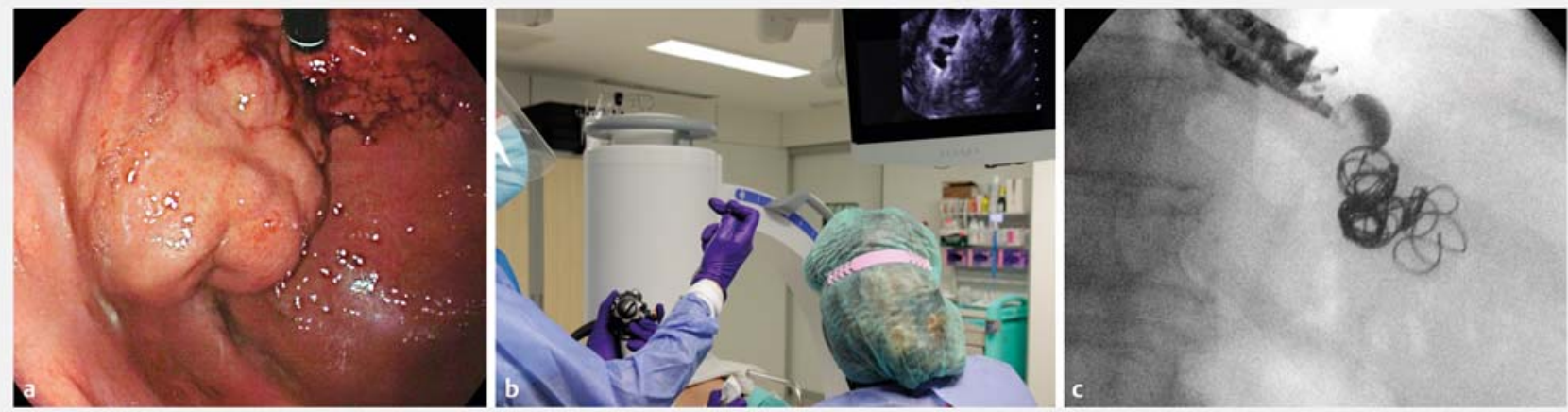

- Fig. 1 Deployment of the embolization coil. a Large, gastric variceal conglomerate in a patient with recent bleeding. b Endoscopic ultrasoundguided transesophageal deployment of a large cylindrical-shaped coil (Nester coil; Cook Medical, Bloomington, Indiana, USA) through a $19 \mathrm{C}$ needle (Echo-tip; Cook Medical). c Fluoroscopy image of multiple coils delivered into a large gastric varix (coil packing).

The procedure is performed under orotracheal intubation. The echoendoscope is positioned in the distal esophagus or in the gastric fundus to visualize the gastric varices; if necessary, water may be instilled into the fundus to improve visualization. Detection of the feeding vessel is unnecessary owing to the complexity of the vessel network and is time-consuming.

1. Preparation: a fine-needle aspiration (FNA) needle is prepared by withdrawing the stylet and flushing with saline $(>2 \mathrm{~mL})$ to avoid the risk of injecting air into the vessel. The coil is preloaded into the needle catheter. Once the needle is confirmed by endoscopic ultrasound (EUS) to be inside the gastric varix, no checking of blood return is needed to avoid blood clotting and no contrast filling (varicealography) is necessary to confirm correct insertion into the target vessel.

2. Coil deployment (Nester Coils; Cook Medical, Bloomington, Indiana, USA): deployment is performed under EUS and fluoroscopic guidance. Larger coils (0.035 inch) are used with $19 \mathrm{G}$ needles, and smaller ones (0.018 inch) with $22 \mathrm{G}$ if needed. The coiled diameter is $10-20 \mathrm{~mm}$ and the straight length is $7-20 \mathrm{~mm}$. Coils are delivered

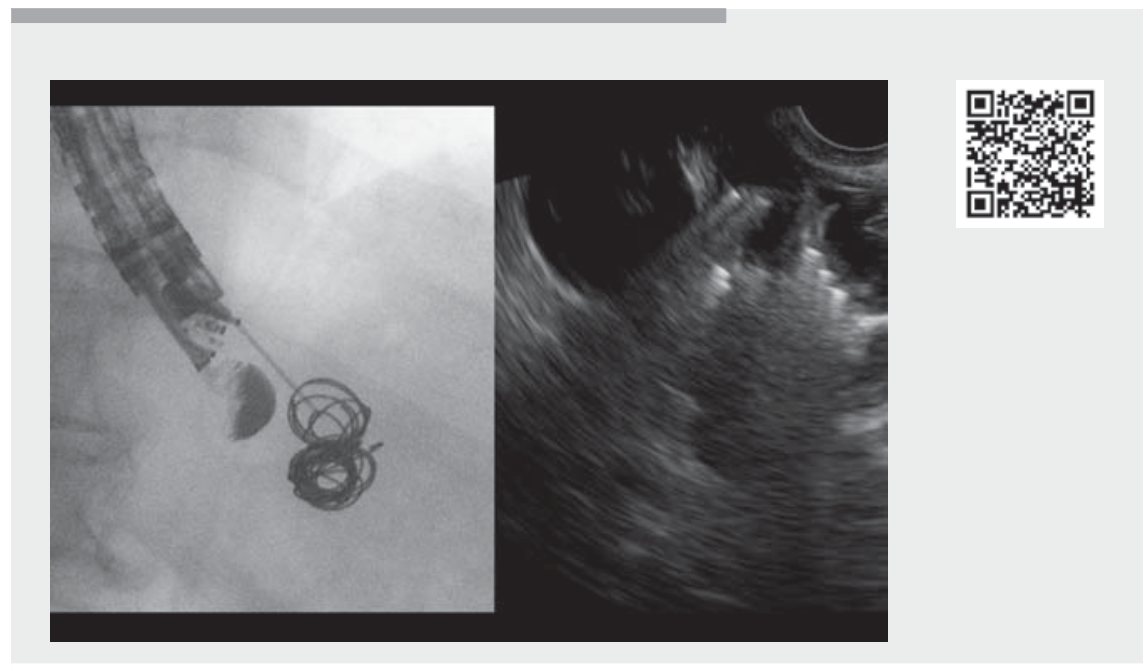

$\checkmark$ Video 1 Nonadhesive massive coiling endoscopic ultrasound-guided embolization in a single session for treatment of gastric varices: learning points of a simple technical variant.

into the varices through the EUS needle, using the FNA stylet as a pusher. The initial coil must be larger to occupy the varix as much as possible to prevent coil migration [1]. Size selection of subsequent coils is based on the remaining vessel space (must be at least larger than the varix diameter on EUS). No special direction of coil deployment is needed ( $\triangleright$ Fig. $\mathbf{1}$,

- Video 1).
3. After several minutes, Doppler is used to confirm absence of flow within the varix; any additional large vessels with persistent Doppler are treated using the same technique. Some Doppler flow may remain; this will reduce with time as a clot is induced by the coil hairs ( $\mathbf{F i g} .2$ ).

There is no standardized approach for EUS-guided coil embolization, and many questions remain about the optimal tech- 

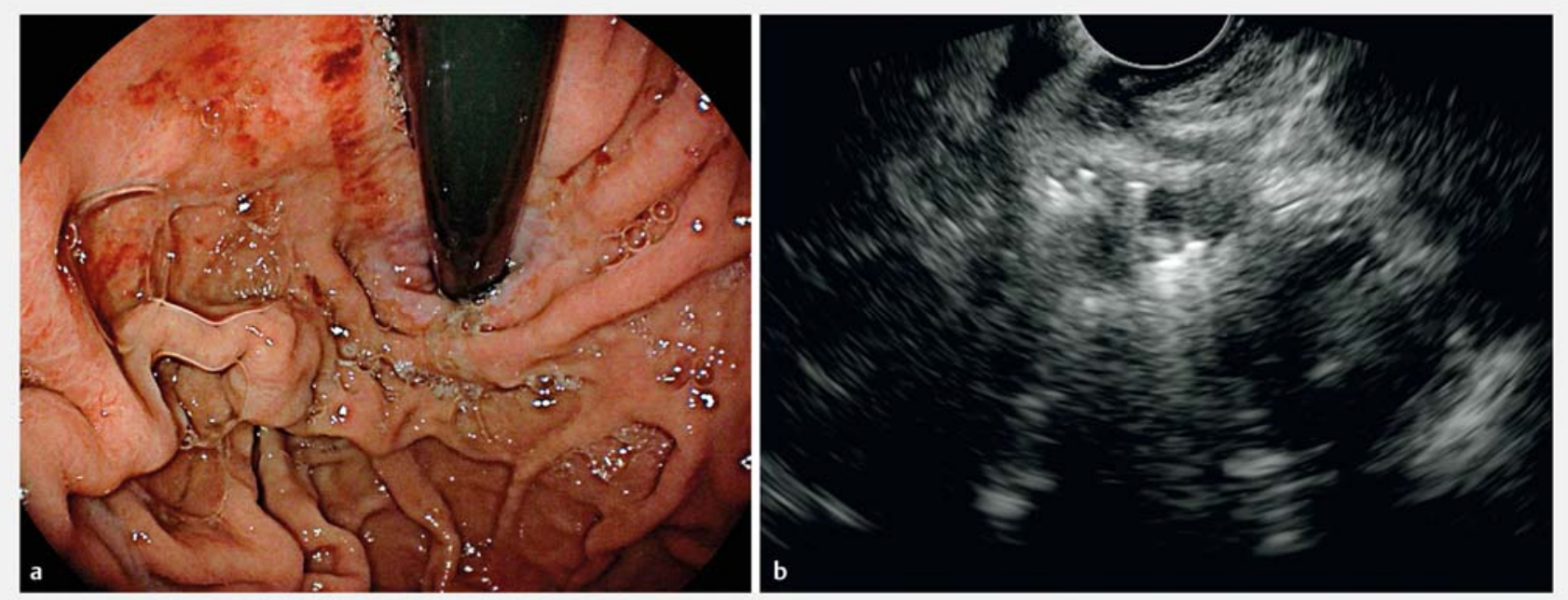

Fig. 2 Follow-up at 3 months. a Endoscopy showed a markedly smaller variceal complex. b Endoscopic ultrasound showed the variceal conglomerate with absent flow on color Doppler.

nique [2-5]. This technique is feasible, simple, and may reduce the reported risk of reintervention compared with the combined (coil plus adhesive) strategy, avoiding the potential risks of using glue.

Endoscopy_UCTN_Code_TTT_1AS_2AB

\section{Competing interests}

JBG is a consultant for Boston Scientific.

\section{The authors}

Albert Garcia-Sumalla' ${ }^{\complement}$, Sandra Maisterra', Alberto Amador-Navarrete ${ }^{2}$, Jose Castellote ${ }^{2}$, Joan B. Gornals ${ }^{1,3}$ (๑)

1 Endoscopy Unit, Department of Digestive Diseases, Hospital Universitari de Bellvitge, Bellvitge Biomedical Research Institute (IDIBELL), University of Barcelona, Catalonia, Spain

2 Hepatology Unit, Department of Digestive Diseases, Hospital Universitari de Bellvitge, Bellvitge Biomedical Research Institute (IDIBELL), University of Barcelona, Catalonia, Spain

3 Faculty of Health Sciences, Universitat Oberta de Catalunya, Barcelona, Catalonia, Spain
Corresponding author

\section{Joan B. Gornals, MD, PhD}

Endoscopy Unit, Department of Digestive Diseases, Hospital Universitari de BellvitgeIDIBELL (Bellvitge Biomedical Research Institute), Feixa Llarga s/n, 08907

L'Hospitalet de Llobregat, Barcelona, Catalonia, Spain

jgornals@bellvitgehospital.cat

\section{References}

[1] Rowley MW, Suarez ]. Coil migration after EUS-guided coil embolization of gastric varices. Gastrointest Endosc 2021; 93: 764765

[2] Thiruvengadam SS, Sedarat A. The role of endoscopic ultrasound (EUS) in the management of gastric varices. Curr Gastroenterol Rep 2021; 23: 1

[3] Bazarbashi AN, Wang T], Thompson CC et al. Endoscopic ultrasound-guided treatment of gastric varices with coil embolization and absorbable hemostatic gelatin sponge: a novel alternative to cyanoacrylate. Endosc Int Open 2020; 8: 221-227

[4] Romero-Castro R, Ellrichmann M, OrtizMoyano $C$ et al. EUS-guided coil versus cyanoacrylate therapy for the treatment of gastric varices: a multicenter study (with videos). Gastrointest Endosc 2013; 78: 711721

[5] Robles-Medranda C, Oleas R, Valero M et al. Endoscopic ultrasonography-guided deployment of embolization coils and cyanoacrylate injection in gastric varices versus coiling alone: a randomized trial. Endoscopy 2020; 52: 268-275
Bibliography

Endoscopy 2022; 54: E228-E229

DOI 10.1055/a-1492-2182

ISSN 0013-726X

published online 31.5.2021

(c) 2021. Thieme. All rights reserved.

Georg Thieme Verlag KG, Rüdigerstraße 14,

70469 Stuttgart, Germany

\section{ENDOSCOPY E-VIDEOS}

https://eref.thieme.de/e-videos

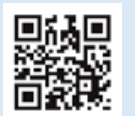

Endoscopy E-Videos is an open access online section, reporting on interesting cases and new techniques in gastroenterological endoscopy. All papers include a high quality video and all contributions are freely accessible online. Processing charges apply (currently EUR 375), discounts and wavers acc. to HINARI are available.

This section has its own submission website at

https://mc.manuscriptcentral.com/e-videos 